
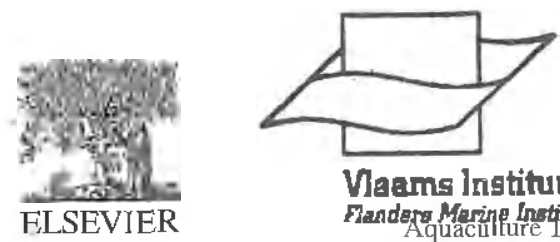

\title{
Fatty acid changes in enriched and subsequently starved Artemia franciscana nauplii enriched with different essential fatty acids
}

\author{
Kyungmin $\operatorname{Han}^{\mathrm{a},{ }^{*} \text {, Inge Geurden }}{ }^{\mathrm{a}, \mathrm{b}}$, Patrick Sorgeloos ${ }^{\mathrm{a}}$ \\ ' Laboratory of Aquaculture and Artemia Reference Center, Ghent University, Rozier 44, \\ 9000 Ghent, Belgium \\ ${ }^{\circ}$ Fìsh Nutrition Laboratory INRA-IFREMER, B.P. 3, 64310 St. Pée, France
}

Received 14 August 2000; received in revised form 27 November 2000; accepted 27 November 2000

\begin{abstract}
The present study aims to evaluate differences in the incorporation efficiency and the possible interactions among highly unsaturated fatty acids (HUFA) during enrichment and starvation of Artemia nauplii. Artemia franciscana nauplii were enriched with emulsions containing docosahexaenoic acid (DHA, 22:6n-3), eicosapentaenoic acid (EPA, 20:5n-3) or arachidonic acid (AA, 20:4n-6) as sole HUFA or with different ratios of these HUFA during $24 \mathrm{~h}$ at $28^{\circ} \mathrm{C}$ and subsequently starved for $24 \mathrm{~h}$ at the same temperature.

The comparison of HUFA incorporation efficiency when supplying the three HUFA separately showed a less efficient enrichment of DHA as compared to AA or EPA. DHA incorporation was always accompanied by an EPA increase, indicating the metabolic convetsion of DHA to EPA by the nauplii during the enrichment process. When offering the HUFA together, we found no competitive interaction of EPA or of AA on DHA incorporation. Only in the case of the $97 \%(\%$ total fatty acids) $n-3$ HUFA emulsion, some negative interference might have nccurred between the HUFA, as it gave a lower incorporation of $22: 6 n-3$ and $20: 5 n-3$ than the emulsions with lower $n-3$ HUFA content.

During the subsequent starvation of EPA- or DHA-enriched Artemia, relative EPA and DHA losses were similarly high in both treatments. In contrast, the presence of DHA in naupliar lipids increased the EPA retention, which might however be related to DHA retroconversion. (C) 2001 Elsevier Science B.V. All rights reserved.
\end{abstract}

Keywords: Fatty acid: EPA: DHA

\footnotetext{
Corresponding author. Tel.: +32-9-264-3754; fax: +32-9-264-4193.

E-mail address: kyungmin.han@rug.ac.be (K. Han).
} 


\section{Introduction}

The dietary requirements of $n-3$ highly unsaturated fatty acids (HUFA), particularly dncosahexaenoic acid (DHA. 22:6n-3) and eicosapentaenoic acid (EPA, 20:5n3), have been documented for various species of marine fish (Izquierdo et al., 1992; Watanabe, 1993; Sargent et al., 1997). DHA, as well as its ratio to EPA, appears to be critical during the early larval stages as it affects growth and survival of marine fish (Kanazawa, 1993; Watanabe, 1993; Reitan et al., 1994; Furuita et al., 1996). Related to its role as a precursor of the eicosanoids, arachidonic acid (AA, 20:4n-6), was later added to the list of dietary essential fatty acids for marine fish (Castell et al., 1994; Estévez et al., 1999; Sargent et al., 1999). The discrepancy between the essential fatty acid requirements of marine fish larvae and the fatty acid composition of their commonly used live prey has resulted in the development of enrichment protocols improving the HUFA content of rotifers and Artemia nauplii (Léger et al., 1987; Takeuchi et al., 1992; Watanabe, 1993; Rainuzzo et al., 1994). Literature data clearly document that DHA, EPA and AA can be incorporated in Artemia nauplii, but also show their catabolism during subsequent starvation (Triantaphyllidis et al., 1995; Evjemo et al., 1997; Estévez et al., 1998, Han et al., 2000b). It remains unclear however if and how the different HUFA interact among each other during the enrichment and starvation processes.

The aim of the present study was to evaluate the differences in fatty acid incorporation in Artemia nauplii when using emulsions containing each of the essential fatty acids (i.e. DHA, EPA or AA) and to examine possible competitive interactions during enrichment and subsequent starvation when using emulsions containing varying proportions of these fatty acids (i.e. DHA/EPA and DHA/EPA/OA (oleic acid); DHA/AA and DHA/AA/OA).

\section{Materials and methods}

\subsection{Diets}

Pure oils of DHA, EPA, OA ( $>95 \%$ purity) and AA ( $40 \%$ purity) were mixed in various ratios (Table 1) before being emulsified. Each lipid emulsion contained $60 \%$ lipid (W.W.), 30\% water, 0.02\% antioxidants (ethoxyquin, Sigma, Belgium). $10 \%$ emulsifier (INVE Aquaculture, Baasrode, Belgium) and $0.1 \%$ vitamin E. The fatty acid composition of the various emulsions was analyzed by gas-chromatography and is given in Table 2 .

\subsection{Cyst hatching, enrichment and subsequent starvation}

Artemia franciscana cysts (ARC. No: 1320) from Great Salt Lake (UT, USA) were used in the experiments. The cysts $\left(4 \mathrm{~g}^{-1}\right)$ were disinfected in a $200-\mathrm{mg}^{-1}$ hypochlorite solution for $20 \mathrm{~min}$ before hatching. After washing with tap water to remove the remaining hypochlorite, the cysts were incubated at a density of $2 \mathrm{~g} \mathrm{l}^{-1}$ in 
Table 1

Combinations of the oils used for preparing the enrichment emulsions for A. franciscana nauplii

\begin{tabular}{ll}
\hline Emulsinn & $\begin{array}{l}\text { Ratio of oils in } \\
\text { emulsions }(\%)^{2}\end{array}$ \\
\hline $\mathrm{DHA} / \mathrm{OA}$ & $50: 50$ \\
$\mathrm{EPA} / \mathrm{OA}$ & $50: 50$ \\
$\mathrm{AA} / \mathrm{OA}$ & $50: 50$ \\
DHA / EPA & $50: 50$ \\
DHA / FPA /OA & $50: 25: 25$ \\
DHA/AA & $50: 50$ \\
DHA/AA/OA & $50: 25: 25$ \\
\hline
\end{tabular}

${ }^{a}$ DHA, docosahexaenoic acid ethyl ester (95\% purity). Itochu Techno-Chemical. EPA, eicosapentaenoic acid ethyl ester ( $95 \%$ purity). Itochu Techno-Chemical, Japan. OA, oleic acid ethyl ester ( $98 \%$ purity). Sigma.

AA, arachidonic acid triacylglycerol (40\% purity). Martek, USA.

filtered seawater at $28^{\circ} \mathrm{C}$ under continuous aeration and light. After hatching, nauplii were separated from the cyst shells and transferred to 2-1 glass tubes (cylindroconical shape) in a water bath at $28^{\circ} \mathrm{C}$ with continuous aeration. The aeration consisted of an open tube at the bottom of the cone and an additional airstone to keep oxygen levels above $4 \mathrm{mg}^{-1}$. Freshly hatched Artemia nauplii were enriched with the respective enrichment emulsions at a dose of $0.2 \mathrm{~g}^{-1-1}$ at the beginning of enrichment $(t=0 \mathrm{~h})$ and after $12 \mathrm{~h}(t=12 \mathrm{~h})$. After $24-\mathrm{h}$ enrichment $(t=24 \mathrm{~h})$, a random sample of 100 nauplii was taken to verify their molting stage (i.e. instar I vs. instars II and III). At $t_{24}$ the surviving nauplii were transferred into a new glass tube at a density of $125 \pm 10$ ind $\mathrm{ml}^{-1}$ and kept in the water bath at $28^{\circ} \mathrm{C}$ for a subsequent starvation of $24 \mathrm{~h}\left(t_{48}\right)$. Each treatment was conducted in triplicate and samples were taken at $t_{0}, t_{12}, t_{24}, t_{36}$, and $t_{48}$

Table 2

Major fatty acid composition (\% of total fatty acids) of the various enrichment emulsions ${ }^{2}$

\begin{tabular}{|c|c|c|c|c|c|c|c|}
\hline & DHA/OA & $\mathrm{EPA} / \mathrm{OA}$ & $\mathrm{AA} / \mathrm{OA}$ & $\begin{array}{l}\mathrm{DHA} / \mathrm{EPA} / \\
\mathrm{OA}\end{array}$ & DHA/EPA & $\begin{array}{l}\mathrm{DHA} / \mathrm{AA} / \\
\mathrm{OA}\end{array}$ & $\mathrm{DHA} / \mathrm{AA}$ \\
\hline $14: 0$ & $0.1(0.0)$ & $0.1(0.0)$ & $0.2(0.0)$ & $0.1(0.0)$ & $0.1(0.0)$ & $0.1(0.0)$ & $0.1(0.0)$ \\
\hline $16: 0$ & $0.3(0.0)$ & $n d^{b}$ & $2.6(0.3)$ & $0.2(0.0)$ & $0.2(0.0)$ & $1.3(0.0)$ & $2.4(0.1)$ \\
\hline $16: 1 n-7$ & $0.2(0.0)$ & $0.6(0.0)$ & $0.2(0.0)$ & $0.2(0.0)$ & $0.2(0.0)$ & nd & nd \\
\hline $18: 0$ & $0.1(0.0)$ & $0.6(0.1)$ & $3.4(0.6)$ & $0.3(0.1)$ & $0.7(0.2)$ & $1.7(0.3)$ & $3.3(0.2)$ \\
\hline $18: \ln -9$ & $50.4(0.9)$ & $49.1(0.7)$ & $66.0(0.5)$ & $26.1(0.8)$ & $0.1(0.0)$ & $32.8(0.6)$ & $17.3(0.4)$ \\
\hline $18: 2 n-6$ & $0.1(0.0)$ & nd & $2.6(0.6)$ & $0.2(0.0)$ & $0.1(0.0)$ & $1.2(0.1)$ & $2.4(0.3)$ \\
\hline $18: 3 n-3$ & nd & nd & $0.1(0.0)$ & nd & nd & nd & nd \\
\hline $20: 4 n-6$ & nd & nd & $19.5(1.1)$ & nd & nd & $10.2(0.7)$ & $20.0(0.9)$ \\
\hline $20: 5 n-3$ & $2.2(0.1)$ & $44.3(1.2)$ & nd & $25.4(0.7)$ & $50.0(1.5)$ & $2.8(0.5)$ & $2.4(0.6)$ \\
\hline $22: 6 n-3$ & $45.8(1.7)$ & $0.7(0.2)$ & nd & $45.6(0.9)$ & $47.0(1.3)$ & $48.4(1.3)$ & $47.2(1.7)$ \\
\hline$n-3$ HUFA $^{c}$ & $48.0(1.1)$ & $45.0(0.9)$ & $\mathrm{nd}$ & $71.1(1.5)$ & $97.0(2.4)$ & $51.2(1.9)$ & $49.6(2.1)$ \\
\hline$n-6$ PUFA & $0.2(0.0)$ & $0.2(0.0)$ & $24.2(1.9)$ & $0.4(0.1)$ & $0.4(0.2)$ & $12.3(1.3)$ & $24.6(1.6)$ \\
\hline
\end{tabular}

\footnotetext{
${ }^{a}$ Minor fatty acids $(<0.1 \%)$ not mentioned in table.

${ }^{b}$ nd: Not detected.

c $>20: 3 n-3$.
} 
after hatching for fatty acid analysis. All samples were stored under nitrogen at $-30^{\circ} \mathrm{C}$ until further analysis.

\subsection{Fatty acid analysis}

The fatty acid composition of the Artemia nauplii was analyzed by a direct transmethylation method according to Lepage and Roy (1984). The internal standard was 20:2n-6. The resulting fatty acid methyl esters (FAME) were separated and identified on a Chrompack CP 9001 gas chromatograph equipped with an autosampler and a temperature programmable on-column injector (TPOCI). Samples were injected on a polar $50 \mathrm{~m}$ capillary column, BPX70 (SGE, Australia), with a diameter of $0.32 \mathrm{~mm}$ and a layer thickness of $25 \mu \mathrm{m}$ connected to a $2.5-\mathrm{m}$ methyl deactivated pre-column. The carrier gas was $\mathrm{H}_{2}$, at a pressure of $100 \mathrm{kPa}$ and the detection mode flame ionization detector (FID). The oven temperature was set to increase from the initial temperature of $85^{\circ} \mathrm{C}$ to $150^{\circ} \mathrm{C}$ at a rate of $30^{\circ} \mathrm{C} / \mathrm{min}$, from $150^{\circ} \mathrm{C}$ to $152^{\circ} \mathrm{C}$ at $0.1^{\circ} \mathrm{C} / \mathrm{min}$, from $152^{\circ} \mathrm{C}$ to $172^{\circ} \mathrm{C}$ at $0.65^{\circ} \mathrm{C} / \mathrm{min}$. from $172^{\circ} \mathrm{C}$ to $187^{\circ} \mathrm{C}$ at $25^{\circ} \mathrm{C} / \mathrm{min}$ and to stay at $187^{\circ} \mathrm{C}$ for $7 \mathrm{~min}$. The injector was heated from $85^{\circ} \mathrm{C}$ to $190^{\circ} \mathrm{C}$ at $5^{\circ} \mathrm{C} / \mathrm{s}$ and stayed at $190^{\circ} \mathrm{C}$ for $30 \mathrm{~min}$. Identification was based on standard reference mixtures (Nu-Chek-Prep, USA). Integration and calculations were done with a software program (Maestro, Chrompack).

\subsection{Statistical analysis}

Data are expressed in absolute amounts $\left(\mathrm{mg} \mathrm{g}^{-1} \mathrm{DW}\right)$ or as relative changes $\left(\mathrm{mg} \mathrm{g}^{-1}\right.$ $\left.\mathrm{DW}^{-1}\right)$ calculated over $12-\mathrm{h}$ intervals as $\left[\left(\mathrm{mg} \mathrm{g}^{-1} \mathrm{DW}\right.\right.$ at time $x-\mathrm{mg} \mathrm{g}^{-1} \mathrm{DW}$ at time $x-12) / 12 \mathrm{~h}$ ] in Table 4. Data represent means of triplicate analysis and were further
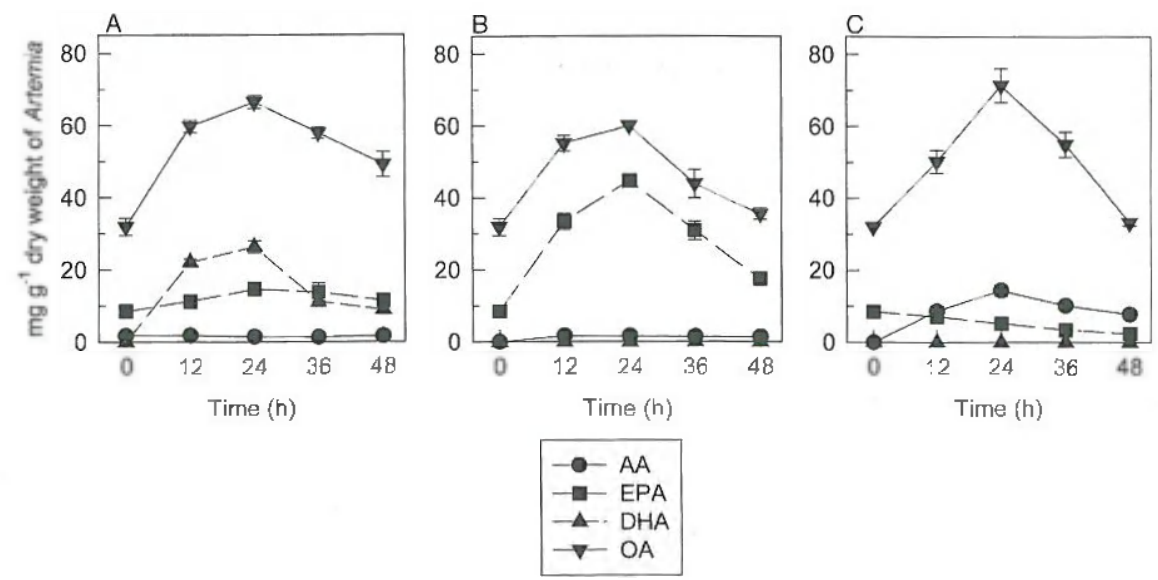

Fig. 1. Changes in the HUFA and OA contents ( $\mathrm{mg} \mathrm{g}^{-1} \mathrm{DW}$ ) in A. franciscana nauplii (SD) enriched for 24 $\mathrm{h}$ with fatty acid mixtures DHA/OA (A), EPA/OA (B) and AA/OA (C) and during a subsequent 24-h starvation. 

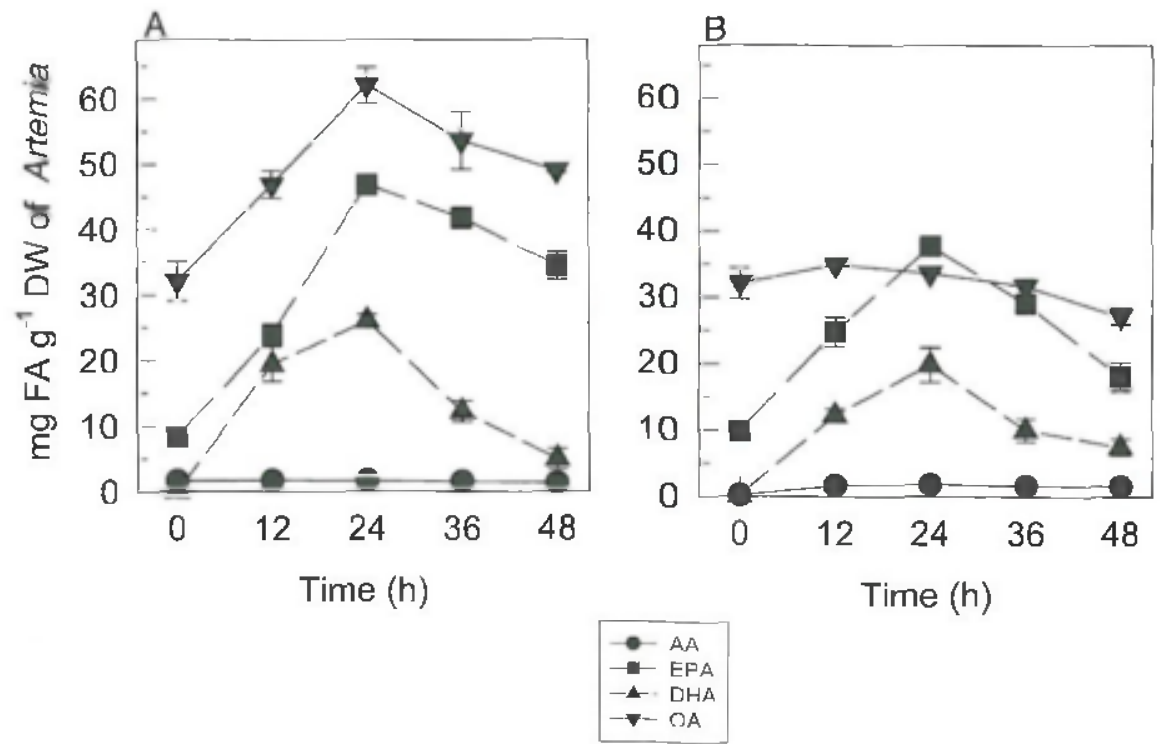

Fig. 2. Changes in the HUFA and OA contents ( $\mathrm{mg} \mathrm{g}^{-1} \mathrm{DW}$ ) in A. franciscana nauplii (SD) enriched for 24 h with fatty acid mixtures DHA/EPA/OA (A) and DHA/EPA (B) and during a subsequent 24-h starkation.

analyzed by one-way ANOVA followed by Tukey's Honest Significant Difference test $(P<0.05)$ (Sokal and Rohlf, 1981).
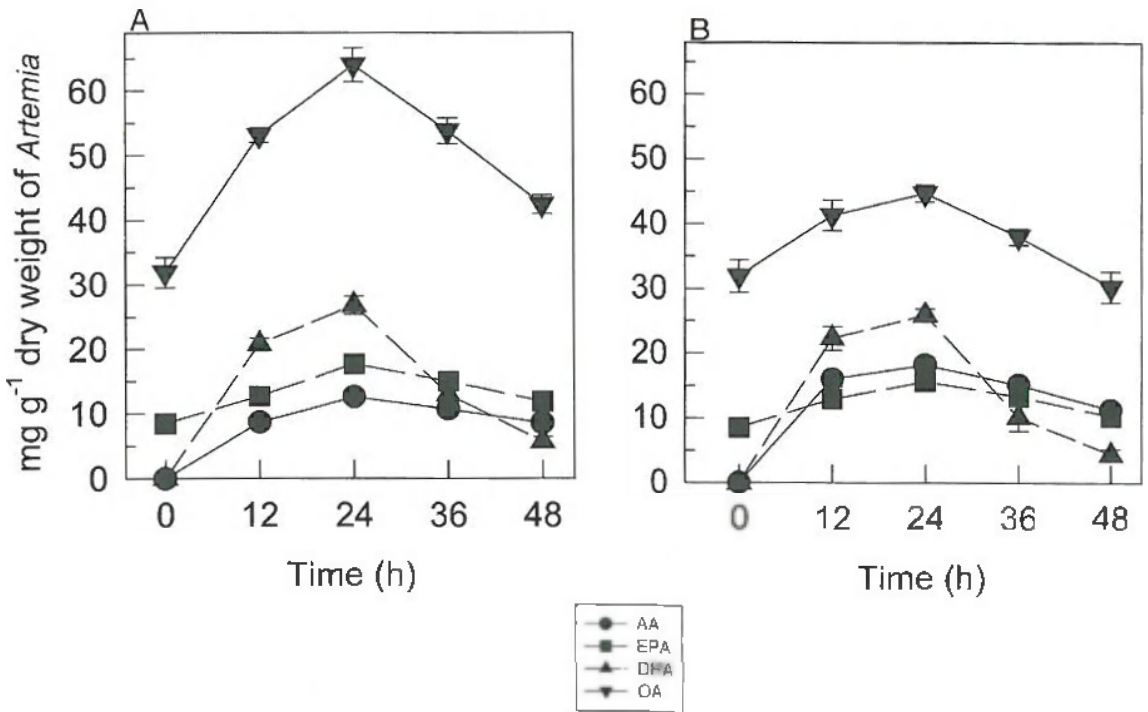

Fig. 3. Changes in the HUFA and OA contents ( $\mathrm{mg} \mathrm{g}^{-1} \mathrm{DW}$ ) in A. franciscana nauplii (SD) enriched for 24 $\mathrm{h}$ with fatty acid mixtures DHA/AA/OA (A) and DHA/AA (B) and during subsequent 24-h starvation. 


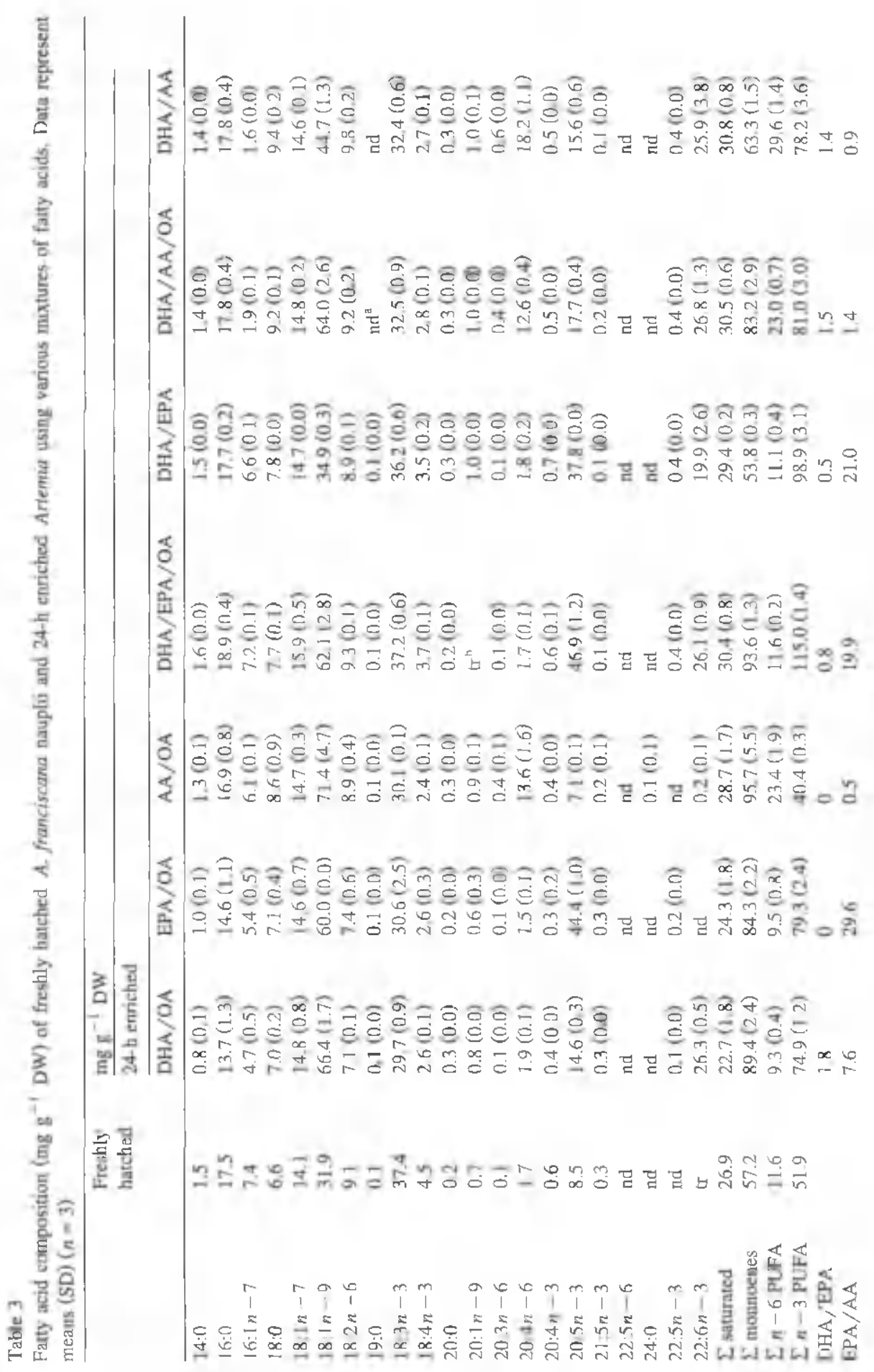




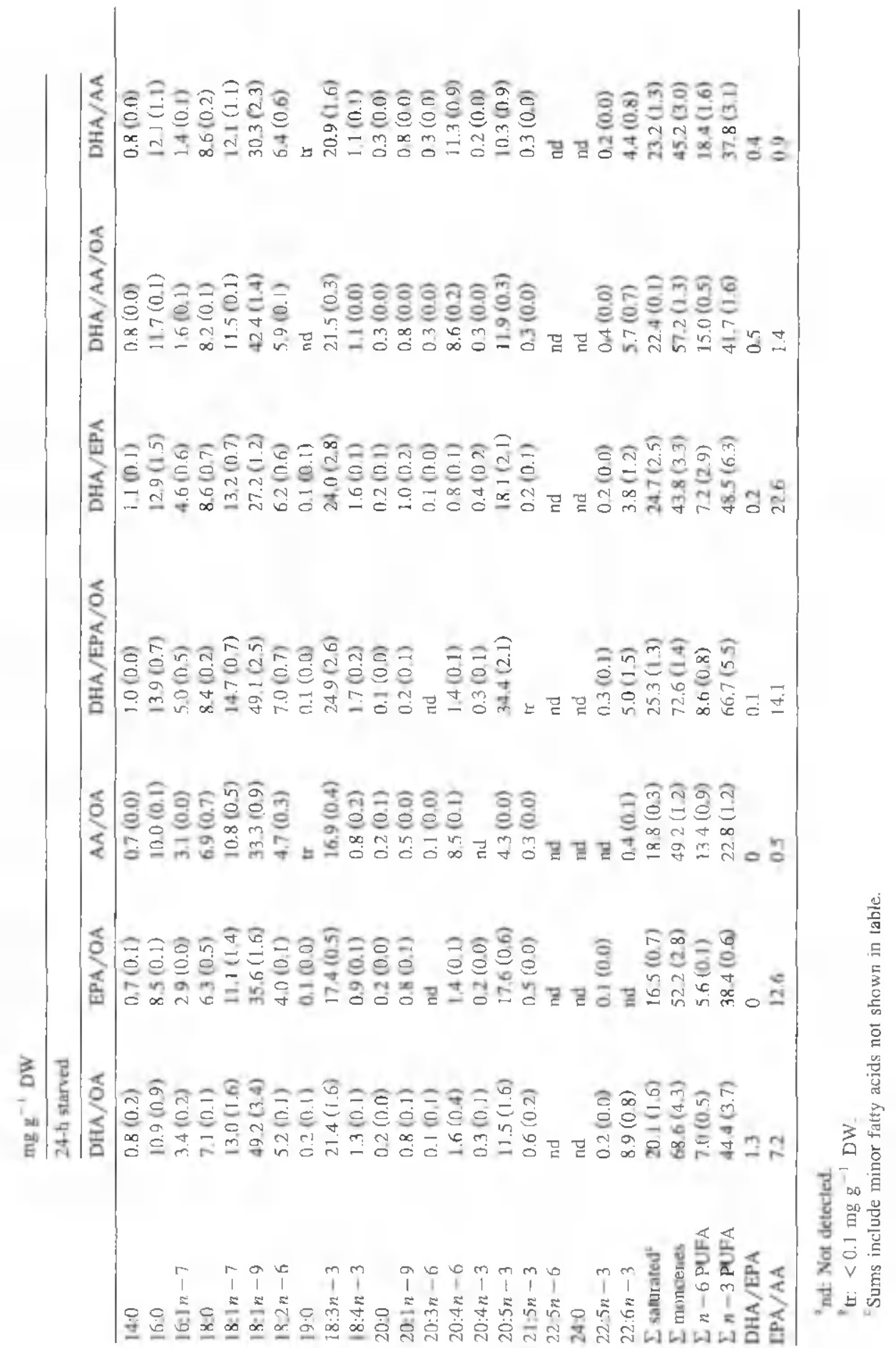




\section{Results}

The fatty acid composition of A. franciscana nauplii enriched with the fatty acid mixtures DHA/OA, EPA/OA and AA/OA is shown in Fig. 1. With the DHA/OA emulsion, the content of $22: 6 n-3$ and $20: 5 n-3$ increased from 0 to $26.3 \mathrm{mg} \mathrm{g}^{-1}$ DW and from 8.5 to $14.6 \mathrm{mg} \mathrm{g}^{-1} \mathrm{DW}$, respectively. In the EPA/OA emulsion, the content of $20: 5 n-3$ increased from 8.5 to $44.4 \mathrm{mg} \mathrm{g}^{-1} \mathrm{DW}$ and in the AA/OA emulsion; $20: 4 n-6$ increased from 1.7 to $13.6 \mathrm{mg} \mathrm{g}^{-1} \mathrm{DW}$. During the starvation period $\left(t_{24-48}\right)$, several changes were noticed in the treatments. In the DHA/OA treatment, the level of $22: 6 n-3$ decreased rapidly from 26.3 to $8.9 \mathrm{mg} \mathrm{g}^{-1} \mathrm{DW}$, whereas the content of 20:5n -3 was only slightly reduced from 14.6 to $11.5 \mathrm{mg} \mathrm{g}^{-1} \mathrm{DW}$. In the EPA/OA treatment, the content of 20:5n-3 decreased from 44.4 to $17.6 \mathrm{mg} \mathrm{g}^{-1}$ DW and in the AA/OA treatment, levels of $20: 4 n-6$ and EPA decreased from 13.6 to $8.5 \mathrm{mg} \mathrm{g}^{-1}$ DW and 8.5 to $2.5 \mathrm{mg} \mathrm{g}^{-1} \mathrm{DW}$, respectively.

The results of the Artemio enrichment with combinations of $22: 6 n-3$ and 20:5n-3 are shown in Fig. 2. In the DHA/EPA/OA emulsion, the content of $22: 6 n-3$ and $20: 5 n-3$ increased during the enrichment period $\left(t_{0-24}\right)$ from 0 to 26.1 and $46.9 \mathrm{mg}$ $\mathrm{g}^{-1} \mathrm{DW}$, respectively. In the DHA/EPA emulsion, the content of $22: 6 n-3$ and $20: 5 n-3$ increased to 19.9 and $37.8 \mathrm{mg} \mathrm{g}^{-1} \mathrm{DW}$, respectively. In the DHA/EPA/OA and DHA/EPA emulsion, the content of $22: 6 n-3$ rapidly decreased during the starvation period $\left(t_{24-48}\right)$ from 26.1 to $5.0 \mathrm{mg} \mathrm{g}^{-1}$ DW and from 19.9 to $3.8 \mathrm{mg} \mathrm{g}^{-1}$ DW, respectively. The content of $20: 5 n-3$ decreased from 46.9 to $34.4 \mathrm{mg} \mathrm{g}^{-1} \mathrm{DW}$ and from 37.8 to $18.1 \mathrm{mg} \mathrm{g}^{-1} \mathrm{DW}$ in the DHA/EPA/OA and DHA/FPA emulsion, respectively.

Fig. 3 shows the changes in fatty acid composition of Artemia enriched with combinations of 22:6n-3 and 20:4n-6. In the DHA/AA/OA and DHA/AA emulsions, the content of $22: 6 n-3$ increased to 26.8 and $25.9 \mathrm{mg} \mathrm{g}^{-1} \mathrm{DW}$, accompanied by a slight increase of EPA to 17.7 and $15.6 \mathrm{mg} \mathrm{g}^{-1} \mathrm{DW}$, respectively. In the DHA/AA emulsion, the content of $20: 4 n-6$ rapidly increased from 1.7 to $16 \mathrm{mg} \mathrm{g}^{-1}$ DW during the first 12-h enrichment period $\left(t_{0-12}\right)$ compared to $8.0 \mathrm{mg} \mathrm{g}^{-1} \mathrm{DW}$ in the DHA/AA/OA emulsion. In the DHA/AA and DHA/AA/OA emulsions, the 20:4n -6 content further increased to 18.2 and $12.6 \mathrm{mg} \mathrm{g}^{-1}$ DW after 24-h enrichment, respectively. During the starvation period $\left(t_{24-48}\right)$, the content of $22: 6 n-3$ decreased more strongly than that of $20: 4 n-6$ and $20: 5 n-3$ in both emulsions. The EPA/AA ratio remained stable during the $24-h$ starvation period (Table 3 ).

Table 4 shows the relative increase and decrease in $\mathrm{mg} \mathrm{g}^{-1} \mathrm{DW} \mathrm{h}^{-1}$ of $22: 6 n-3$, 20:5n-3 and 20:4n-6 during the enrichment and subsequent starvation period for all the emulsions. During the first enrichment period $\left(t_{0-12}\right)$, the increase of $22: 6 n-3$ in the DHA/EPA emulsion was significantly $(P<0.05)$ lower than in the other treatments, which contained the same 22:6n-3 concentration (DHA/EPA/OA emulsion, $50 \%$ of the emulsion). In the second enrichment period $\left(t_{12-24}\right)$, no difference in 22:6n-3 uptake was noticed. The $22: 6 n-3$ level decreased more rapidly during the first starvation period $\left(t_{24-36}\right)$ than during the second starvation period $\left(t_{36-48}\right)$. The increase of 20:5n-3 with the EPA/OA emulsion during the first enrichment period $\left(t_{0-12}\right)$ was significantly $(P<0.05)$ higher than with the DHA/EPA emulsion and even 
Rainuzzo, J.R., Reitan, K.I., Olsen, Y., 1994. Effect of short and long-term lipid enrichment on total lipids, lipid class and fatty acid composition in rotifers. Aquacult. Int. 2, 19-32.

Reitan. K.I.. Rainuzzo, I.R., Olsen, Y.. 1994. Influence of lipid campositjon of live feed on growth, survival and pigmentation of rurbot larvae. Aquacult. Int. 2, 33-48

Sargent, J.R., Bell, J.G., McEvoy, L.A., 1997. Requirements, presentation and sources of polyunsaturated fatty acids in manine fish larval feeds. Aquaculture 155, 117-127

Sargent, J.R., McEvoy, I., Estévez, A., Bell, G., Bell, M., Henderson, J., Tocher, D., 1999. Lipid nutrition of marine fish during early development: current status and future directions. Aquaculture 179, 217-229

Sokal. R.R.. Rohlf. F.J.. 1981. Biometry. Freeman. New York, USA, 859 pp.

Takeuchi, T., Toyota, M., Watanabe. T.. 1992. Comparison of lipid and $n-3$ highly unsaturated fatty acid incorporation between Artemia enriched with various types of oll by direct method. Nippon Suisan Gakkaishi 58, 277-281.

Triantaphyllidis, G.V., Coutteau, P., Sorgeloos, P., 1995. The stability of $n-3$ highly unsaturated fatty acids in various Artemia populations following enrichment and subsequent starvation. In: Lavens, P., Jasper, E, Roelants, I. (Eds.), Tarvi 95 Fish and Shellfish Symposium. European Aquaculture Society, Special Publication, vol. 24, pp. 149-153.

Watanabe, T., 1993. Importance of docosahexaenoic acid in marine larval fish. J. World Aquacult. Soc. 24. $152-161$

Watanabe, T., Oowa, F., Kitajima, C., Fujita, S., 1978. Nutritional quality of brine shrimp, Artemia salina, as a living feed from the viewpoint of essential fatiy acids for fish. Bull. Jpn. Soc. Sci. Fish. 44, 1115-1121. 
... 